\title{
JUSTICE, WAR AND COMMUNAL SUBCONSCIOUSNESS
}

\author{
Kuno Janson, Associate Professor Emeritus, Tallinn University of Technology \\ kuno.janson@ttu.ee
}

Summary by the author of the book with the same title

\section{PROLOGUE}

We live at a wonderful time. The standard of science and technology is higher than ever before. We use different amenities and have no idea of their complex development process. At the end of the last century $(1980-2000)$ the economic growth rate was high and there were no acute global problems. It seemed that human history had entered into a new happy era.

Yet at the beginning of the 21st century, the situation has changed. The economic growth rate is tending towards zero and people talk about a global development stagnation. There are colourful revolutions, the failure of the Greece state, the military success of radical Islamic groups and an enormous flow of war refugees to Europe. There is a tension in interstate relations and the threat of nuclear war has become real again.

What is the matter? Is it that the people of the end of the 20th century were competent and successful and the people of the beginning of the 21 st century are incompetent? Or perhaps there has been an uprising of some mystical forces that are not human?

Why are social scientists not explaining the situation and solving the problems that have arisen? Why do they not show us how to avoid the spontaneous polarisation of the global community with an accompanying absurd mutual hate? Why do they not explain how to come to a mutual understanding and solve problems in such a way that every party would be satisfied and happy? No one needs the fear of nuclear war. At the moment, however, general conflict that no one can stop is sneaking in and substituting former smooth cooperation.

The situation in our current world shows clearly that sociologists are not of the required standars to prevent or solve already existing problems. Can we see any distinct efforts to develop the social sciences? Unfortunately not. On the contrary, there is a dominating opinion that science has already thoroughly covered all essential fields and only some minor details are still unclear.

On the one hand there is an acute need to solve problems and at the same time an incapacity to do so. On the other hand it is still considered that we are capable of everything and can control everything. How might we explain this seemingly schizophrenic situation?

Let us consider the situation in more detail. If all human beings were totally controllable like robots then we obviously would have no problems with creating order and harmony. Engineers would set the world to function properly as they do with any other mechanism.

What do the social sciences say about humans as controllable and reasonable beings? The difference between humans and robots is that humans have the intuition and the ability to invent things. Robots only follow set programmes. The thoughts of humans are unpredictable, 
which is an extraordinary phenomenon in nature. Intuition is created in the human mind. It does not enter the mind from external sources through unknown pathways.

What does information theory say about humans' extraordinary intuition and thinking process? Information theory is part of mathematics. Mathematics is applied without exclusions everywhere in the universe. No anomalies have been discovered. The human thinking process should also follow the common rules of information broadcasting and information processing. Information theory states that in a system (e.g. in the human mind) new information can be created only in ranges that are enabled by the processing of existing data. In other words, new information can be there only as a conclusion based on existing data.

Let us consider what an invention is. In the patent business an invention or a discovery is considered information that is not possible to conclude on the basis of the existing knowledge available to humankind. Patent institutions assess whether a patent application qualifies as an invention, or whether in fact it is possible to come to these conclusions on the basis of an existing technology. An invention is only something that is not possible to get to know in any known way.

Here we have a contradiction. It is commonly believed that an invention is created in the human mind. Information theory states that for this process prior information is required that forms the basis for the possible discovery. Yet at the same time patent institutions check that there is no such prior information anywhere in the world. Therefore, invention should be impossible altogether.

If we, however, assume that information may also enter a person's mind in unknown ways, then an invention is possible. For an invention one needs unknown pathways for the information sources and transfer. The explanation that states that an invention or a discovery could only be made by using known pathways and sources of information transfer appears therefore to be dismissive. This is not, however, accepted by mainstream.

Besides mainstream science there also exists front line science with different views. Front line science also deals with half-known phenomena that are between the world that is covered by mainstream science and the world that is currently beyond the reach of science.

According to front line science, there exist information sources that are unacceptable to mainstream science where information is carried by structural changes in a vacuum or fields that are created by the effect of energy. A vacuum is not an absolute emptiness but a very special sparse substance.

Front line science also states that there exist fields that cannot be generated or registered by contemporary technical tools but that biological objects have the capability to generate, sense and use these fields for communication.

According to front line science, besides the conscious mind humans also have a subconscious mind and the unpredictability of human behaviour is merely determined by an extensive information processing that happens in the subsconscious mind, which humans themselves cannot sense. Furthermore, there exists a collective subconscious or a communal subconscious that corrects the thinking process and behaviour of all humans who have the same identity. If that is the case then information is transferred from person to person through thus far unknown ways through the air, unnoticed by humans. The communal subconscious is described in the book that is summarised here.

The communal subconscious also includes values. It ensures that all humans with the same identity have the same values. This is achieved through the subconscious blocking 
incongruent information. For instance, if one tries to prove to a person whose values dictate that all humans descend from Adam that humans have been developed through the process of evolution then the subconscious steps in and blocks all information that contradicts humans descending from Adam. In the case of the blocking process the subconscious distorts information to such an extent that when it reaches a person's consciousness the content of the message has become incomprehensible and ridiculous and the distorted message will be forgotten as nonsense.

Front line science says that the human psyche has a subliminal collective component. Due to the manipulating effect of the collective subconscious the human thinking process appears to be unpredictable and special. If we take the the collective component into consideration then the unpredictability disappears.

Mainstream science, however, ignores the existence of the collective subconscious and its effect and that is why human thought in its full extent seems inexplicable. That is why it is thought that it is not possible to control humankind in the same way as, for instance, a product line with robots. The same reason is attributed to why social scientists cannot solve the current problems mentioned above. Mainstream science explains that the partial conflict of certain values between the Islamic world and Western countries cannot be overcome because the information process in humans ' heads follows different rules than a computer and these rules are unknown to us.

Mainstream science appears to place the human thought process into a sort of a black mystical box where different natural laws apply than anywhere else in the world. One cannot enter into that black box therefore no one can control a person's thought or social processes enough. One cannot do anything except watch as the world progresses towards war. Declaring the human thought process special and inexplicable and placing it in a black box is not, however, justified. This derives from the unreasonable assumption that the human thought process follows special unknown rules. In view of front line science that assumption seems to be a mistake.

The information that is stored in the communal subconscious one can be detected only approximately, by following the behaviour of humans who have a shared identity. Questionnaires about public opinion might not provide the correct information. Normally humans do not even know what is written into their subconscious. A person's behaviour can sometimes surprise even themself.

The information that is stored in the communal subconscious changes relatively slowly and only when it is affected by certain events that occur in a society. If we know how events in the society change the information in the communal subconscious and also what kind of effect it has on humans behaviour, then it should be possible to some extent to predict the future. Studying subconsciousness should reveal hidden social processes that could be used to avoid major crises and wars. This is one of the main topics of the book that is summarised here.

It is also useful to know that in a person's head there may exist obsessions caused by identity. Almost no one suspects that they could have any mistaken obsessions. We almost always think that it is the opposition that makes mistakes. Talks between Russia and Western countries, for example, have come to a dead end. And neither party knows the actual reason for the misunderstanding - unchangeable groundless opinions that are in the negotiators' heads, which function as values. Not accepting even mistaken values creates spontaneous anger. Anger can make one so blind that one cannot understand simple things anymore and talks come to a dead end. 
Front line science considers religion to be one form of communal subconsciousness. Mainstream science, on the other hand, considers religion to be an inexplicable aspect of human thought. The main obstacle that prevents normalising relations between civilisations is not understanding religion's essence and role. Threats that can emerge from the ideological confrontation linked to the islamisation of Europe are also not recognised.

To overcome the dangerous and irrational conflict between civilisations it is absolutely necessary to inform the public about the biological nature of human thinking. The correct theory, disseminated to the masses is an enormous force. Front line science has, however, thus far reached the masses although Carl Gustav Jung already discovered the communal subconscious approximately one hundred years ago. People like to think of themselves as the crown of the nature with an inexplicable mind.

There are some people whose mind is not significantly affected by collective obsessions. They have also been called dissidents. These people can understand the problem and accept the existence of the communal subconscious. These people communicate. Through these people and their communication circles, the old myth starts to crumble. Slowly, people will start to consider the role of subconscious obsessions adequately. In the end, even the big conflicts that cause the threat of war should disappear.

Nevertheless, at the moment mainstream science still supports a mistaken worldview about human nature, which is a myth, and ignores the communal subconscious. This myth hides a peaceful way out of the modern universal ideological conflict. To solve the problems through war following "the stronger person is always right" principle is almost suicide for the globalised and urbanised modern world. Simply cutting off the electricity supply causes total chaos in a modern city. But war does not only cut off the electricity supply. There is little hope that nuclear bombs will not be used. Unfortunately, the history of humankind is a history of wars. It would be naïve to think that a tradition of solving disagreements through war that spans millennia will suddenly disappear by itself.

Does this worry anyone? It may well do, but one human being cannot achieve much. One human being cannot change the world. It is true. But one human being can share their worries with another and that already makes two. And when these two share their worries then it makes four. And if they carry on that way then it soon makes many of them. Many people together can find a solution and also put it into practice.

It was during the Cold War in the second half of the $20^{\text {th }}$ century that the peace movement started. The development of the global world was at that time in an upward spiral. No one wanted to lose his or her lives because of some stupid war. But now the world is in a downward spiral. Wellbeing is decreasing. Many people are bitter. An attitude has emerged along the lines of: I am not the one who should keep holding up this disgusting world. It may fall apart but I do not care. This attitude has been called pohhuism and it has started to spread like a contagious disease. It is comfortable because one does not have to take responsibility for anything. It supports the bad habit of laying the blame onto others.

Yet if we face the truth honestly then we all are responsible for the wellbeing of the world. We have different possibilities but every one of us can do something. Reasoning that I cannot, or do not want, or that it is not needed, is self-deception. 


\section{Part 1. Collective stubbornness}

\section{Overcoming disagreements}

The history of the world, to a large extent, is the history of wars and conflicts. The next big war could be an atomic war. Are wars inevitable? What causes wars?

Wars begin because of disagreements. Life shows that in the majority of cases discussion and exaplanations can solve disagreements and conflicts. That does not always work out, however, and conflicts escalate into the use of violence. The use of the violence means mutual harm and destruction. Outsiders think that it is nonsense because an agreement would be more sensible. Affected parties do not think so. At least not at first.

Conflicts exist on all levels - between states, societal layers (entrepreneurs and employees), even in family relations. Unsolved disagreements do not have to lead to war right away. Disagreements and conflicts can linger for decades, affecting parties negatively. Deep unsolved disagreements have always been a serious problem and continue to be so at present.

\section{What is done when disagreements arise?}

One way is to seek consensus. Listening to the opposing party, highlighting common aspects, seeking reasons for disagreements together. This tendency was widespread after the Second World War. Unfortunately there are situations where reaching mutual understanding is not possible.

The other way is to force your opinions onto others. One believes that one is never mistaken and does not listen to the opposite party. Nowadays forceful actors are often admired and imitated. It is believed that force makes you right. This approach is, however, unfair and keeps the seeds of conflict alive. When the situation changes, the conflict is back.

The third way is to praise the abundance of disagreements. Truth-seeking is never even endeavoured. Everyone can believe whatever they like. That is the modern version of organising a democratic society. The basis for this is the opinion that a human being is sometimes unable to understand everything, no matter how thoroughly it is explained to them. People with similar opinions form their own party and when they come to power all the others have to agree with them. It is acknowledged that democracy has deficiencies but it is added that "do not start to change anything, it only makes things worse". Silently it is hinted that it is not possible to change collective stubbornness and it is wiser to agree with it.

While speaking about democracy the reason why democracy is needed is almost never mentioned. Why is reaching a common understanding practically impossible in the majority of cases? Science views humans as rational beings that are capable of understanding everything if a reasonable explanation is provided. But the need to use democracy shows the opposite. Is it not time to start to correct these views about human nature? About the information that people accept and that which they do not accept in any circumstance. Perhaps this stubbornness is not illustrative of the deficiency of the capacity of understanding but rather something unknown?

\section{The terrorist attack in New York on September 11 ${ }^{\text {th }}, 2011$}

On the 11th of September 2011 the commercial aeroplane that was hijacked by the suicide terrorist group al-Qaeda rammed into the World Trade Centre in New York. The building was destroyed. 
The first natural question would be why they did they do it. George W. Bush, the President of USA at that time answered this question in his TV broadcast. Bush said that the attackers should have no hope of affecting us because we are sure of our values.

So the most general reason was the difference of values. The values of the Islamic world did not match with the values of the Western world. George W. Bush followed the principle that one cannot trade with values. Islamist suicide attacks show that they also stick to their values, to the death. This stout opposition has caused both - the terrorist attack on September $11^{\text {th }}$ and wars in Iraqi and Afghanistan. These wars have caused enormous human suffering and financial expenses. So far neither party has been significantly successful. Conflict like this seems meaningless. Huge expenses of military technology, training, equipment, compensation of health losses, destroyed buildings and structures, enormously expensive security of air transport all over the world. Woul it not be more reasonable to talk things through and live in peace? The economic impact would be enormous. Why is such an agreement not possible?

Western democrats are convinced that Allah does not exist and Islamists are some kind of a mental failure.

Islamists on the other hand think that all people who deny God are the mental failure. This failure is the underdeveloped human psyche. Believing in God is generated on a higher level of human development. People who do not believe in God are underdeveloped.

Both parties have a nice explanation that excludes actually studying the problem. There is no reason to study neither the thoughts of a crazy person nor why an ape does not think in the same way as a human being.

Is the failure to understand that is characteristic of people who are blind to religion only connected to religion, or could it also be connected to some non-religious ideology like communism, fascism or overstressed consumer ideology?

\section{The Cuban crisis}

From history we know of the so-called Cuban crisis in October 1962. It was a conflict between the USA and the former Soviet Union. The Soviet Union located nuclear rockets in Cuba. This conflict almost lead to nuclear war. The deeper reason for this conflict was the conflict of values between the communist ideology and Western ideology. Neither ideology was connected to religion. Therefore collective stubbornness does not have to be connected to religion.

\section{The conflict between entrepreneurs and employees}

The collective stubbornness also manifests itself between different layers of society. Well known is the conflict between entrepreneurs and employees where both parties have their own ideology. There are deep long-term disagreements between these ideologies. The motive for creating the communist ideology was to solve the problem of dividing the wealth that was gained by communal work fairly. The essence of the problem is that entrepreneurs and employees identify themselves as belonging to different communities. Both the community of entrepreneurs and the community of employees have their own set of values and both ignore the opinions of the opposition. This could also be called the blindness of identity. Two types of thinking are used. A negative picture is created and the opposition is dehumanised. The roots of this thought pattern are old. The proletarian or left principle: values are created by employees and belong to them. The other principle, on the right, is as good: money is created in businesses and belongs to the entrepreneur. The conflict is between two identity circles.

Carl Gustav Jung (1895-1961) showed that one part of identity is the collective subconsciousness. The collective subconsciousness includes permanent ideas and images that 
Jung called archetypes (e.g. Me, Hero, Underworld). The archetypes are emotional forms of thinking where the tracks of the humankind's past experiences are stored. The archetypes are in a way similar to all people and are passed from generation to generation as instincts.

There is reason to believe that the conflict between entrepreneurs and employees is connected one the one hand with very old values that are stored in the collective subconscious and on the other hand with the fact that the enterprising is a relatively new phenomena and the new principle to share the results of collective work fairly that would of been accepted by all on the level of the collective subconscious has not yet been developed.

\section{Disagreements in science}

There are disagreements also in science. Mainstream statements are socially accepted. Front line science statements are often not accepted for a long time. British biologists Rupert Sheldrake studied the existence of a telepathical information channel between dogs and their owners. Experiments were as follows. Both dog and owner were filmed at the time when the dog was at home and the owner was not. The owner could receive phone calls at any time (timing was unknown both to the owner and to the dog) and was asked to go home straight away. Exactly the same time the dog ran to the door to wait for him. This experiment has been controlled hundreds of times and could be seen as scientifically proven. But then one should acknowledge that science could not explain how information transfer such as this from the owner to the dog is possible. Mainstream science uses a default principle: that which science cannot explain does not exist. Mainstream science simply ignores the results of Sheldrake`s experiments.

Collective stubbornness also dominates in science. From a scientific point of view one cannot speak of people's blindness to religion or greed. These disagreements are between scientific communities. These disagreements are caused by blindness to identity.

\section{Collective stubbornness is dictated by the communal subconsciousness}

\section{In the identity circle there is spontaneous opposition to the breakers of generally accepted principles}

Normally scientists approach all phenomena of the environment calmly and rationally. If something, however, touches principles that are enormously important to them then scientists become normal people who cannot stay calm in relation to all opinions that they hear. If, for example, a mainstream scientist sees a text that seriously studies telepathy then the paper is thrown in the rubbish bin without carefully considering it and in the same way the computer file is deleted. At earlier times "wrong" books would have been burnt. If one hears an irritating opinion in a talk then one remembers nothing but a stupid story. The message and argumentation do not reach the mind. Football fans have the habit of using fists against the deliverer of a "wrong opinion". Usually each football club has its own fans that form a gang of kindred spirits. Different gangs watch one and the same game but get very different impression of it. After the match a fight between gangs is not rare.

\section{In everyday life one behaves according to generally accepted principles}

Peer pressure behaviour is particularly visible in conflict situations. Peer pressure behaviour is in fact also very common in everyday life where it is not so visible because it is familiar. Imitative behaviour helps to save time and energy consumption. It is not necessary to start solving every problem from zero. It is sensible to use others' experience. The knowledge and experience of humankind compared to one human`s knowledge and experience is colossal. 


\section{Imitative behaviour is largely subconscious}

Other people's experiences are always used, but no one notices that broad mutual imitating happens. Everyone feels that the decisions they make are personal ones.. The impression that decisions are personal forms because people really do come up with good thoughts. But if we take a closer look then it becomes clear that these good thoughts that enter our consciousness come from the subconscious. The subconscious mind is older than the conscious mind. The information processing capacity of the subconscious is about 40 nerve impulses per second. The information processing capacity of the conscious mind is about a million times smaller. About $95 \%$ of our decisions, actions, emotions and behaviour are based on the unnoticed information processing of the subconscious mind. The subconscious gives us our everyday mind that magnificently solves everyday tasks. But for totally new tasks the everyday mind that uses the subconscious gets into trouble. Studies have shown that programming the subconsciousmind starts already in the womb and is largely complete at 6 years old. Aside from the individual level subconsciousness also has a group and community level and a general collective level that includes all people as Jung has described. Information is transferred to the individual level also from levels that are shared with others. The nonindividual subconsciousness could be called the communal subconsciousness in order to distinguish it from the collective subconsciousness that Jung has used. Different community circles and identity circles have their own communal subconsciousness. The thoughts that come from the communal subconsciousness have also been called a gang spirit. The content of a person's opinions is highly dependent on which gang, society or community they belong to. Identity brings with it many different viewpoints and values from the subconscious . Different information in the different communities' communal subconsciousness causes collective stubbornness.

\section{Social opinion shapes individual opinion}

When someone does not behave according to social norms then it brings to the surface a general negative attitude. The consequence for following or neglecting social norms is praise or punishment. You have to follow the rules due to pressure from your peers. An opinion different to the common view may also cause negative attitudes. Individual opinion is shaped by pressure from public opinion. The statement that public opinion is determined by many independent individual opinions is incorrect. Despite unnoticed dictated rules of behaviour and thinking people also have a certain amount of freedom. This freedom allows one to move as much as a dog kept in a chain. The chain for the dog could be longer or shorter. A society can allow more or less freedom for its members. The bigger the freedom the less there are rules that keep society together. There is the danger that when there are too few rules left then the society falls apart. How much freedom is optimal is determined by how developed the society is and its natural conditions.

\section{Imitating incorrect behaviour}

Dictated imitative behaviour also has its negative side. It is possible that people would start to imitate the person who acts incorrectly. Then the error would intensify and potentially have dire consequences. Collective stubborn behaviour in conflict situations should be seen as a special case of imitative behaviour where, among other things, an incorrect behaviour is imitated.

Usually in a conflict situation both parties use some incorrect argumentation. Let us come back to the conflict between entrepreneurs and employees. Employees think that all production in an enterprise is their doing and should belong to them. They are mistaken because production without making materials available, marketing and managing the whole process would not produce a result with the necessary monetary value. The entrepreneur feels 
that all profit is the final result of their business plan and investment. The entrepreneur is mistaken because an employee cannot be equalised with a workhorse in terms of sharing the profit. Employees subconsciously consider this kind of approach as a violation of justice and conflict is inevitable.

Just as normal imitation is mainly subconscious, incorrect imitation is also mainly subconscious. A community's stubborn behaviour in conflict situations is due to the fact that all members of a community have the same incorrect opinions in their subconsciousness. This causes large unsolved conflicts in the long-term. But no lie becomes the truth just because millions of people believe it.

Even if crystal-clear arguments revealing an error are recounted, it still does not convince anyone. It seems that collective opinion is usually connected to the communal subconsciousness and therefore you cannot change it through persuasion. People in an identity circle are not able to recognise their common mistake. Dissidents who do not obey the terror of common public opinion are an exception but there are few of them. However, from an outside perspective it is relatively easy to notice incorrect opinions in the identity circle.

\section{Unsolvable conflicts are caused by obsessions that secretly accompany identity}

If conflicts that have emerged as a result of collective stubbornness are compared, those between different religions, states, scientific schools, gangs of football fans or between workers and entrepreneurs, it becomes cleart that they have many similar features.

- All opinions that contradict the values of an identity circle (or a gang spirit) more or less evoke an angry reaction. The argumentations of these opinions are not listened to. If the question concerns an ideological scientific conflict, and it is inevitably necessary to either contradict the arguments of opposition or to agree with them, then nevertheless one finds a way to basically look past the content of the problem. For instance, the argumentation of the opposition is distorted and then criticised as if this distorted version belonged to the opposition. One acts as if reaching a consensus were impossible. Sometimes it is also said, somewhat arrogantly, that we do not trade our values.

- In the case of collective unsolvable conflicts by rule both parties act perfectly normally. Generally neither party could be blamed for deliberate malice or pathological psychology. One acts according to one's best understanding. The reasons for collective conflicts are delusions on the level of communal subconsciousness and generally one cannot change this delusion just by talking.

- Parties in a conflict see the behaviour of the opposition as incomprehensible and abnormal.

It would be important to know what possibilities there are for erasing a collective delusion. Collective opinions are not infinite. New opinions arise and old ones disappear. If we want to avoid the unpleasantness brought about by collective incorrect behaviour then we should study how people in an identity circle accept a new opinion and let go of an old one. 


\section{Part 2. Forming and changing communal subconsciousness}

\section{How are public opinion and values created and changed?}

The mechanism of changing values has been studied quite well in relation to how a society accepts changes. At first one person has an innovative idea and they put it into practice. Almost everyone else thinks that this innovation is weird and absurd. After some time the number of people using that innovation nevertheless starts slowly growing. But it happens only if using that innovation has a beneficial outcome. When the number of people using the innovation has grown to approximately $10-20 \%$ of active people in the community, something similar to an explosion happens. It is as if almost everyone realised during the night that the innovation is very reasonable and useful. The stage when the innovation is put into practice forms automatically. It is well known that people are incline to imitate each other. If one person puts an innovation into practice (e.g. starts storing a rapidly spoiling food supply in the fridge) and communicates with two people who imitate him or her and also put the innovation into practice then on the first level of the communication circle we have two imitators, on the second level $2 \times 2=4$ imitators, on the third level $4 \times 2=8$ imitators, on the fourth level $8 \times 2=16$ imitators etc. If $20 \%$ people have accepted an innovation already, then on the next level there will be $40 \%$ imitators and the step after this will take the number to $80 \%$. This process is called a chain reaction. In the end of the process the growth of the number of imitators accelerates enormously - it seems that finally everyone puts the innovation into practice at the same time as if in response to some signal that came from somewhere. In reality there are just individual decisions.

The stage when innovations are rapidly put into practice is basically a mass behaviour. Large numbers of people think and act in the same way and at the same time. Elias Canetti (19051994) has studied mass behaviour and has found out that a mass is formed right away when many people think and act in the same way. People who are together form a common subconsciousness that manifests itself as a mass behaviour. Canetti has described the formulation of a mass using a theatre audience as an example. During the performance everyone is involved in the same activity - they follow the performance and enjoy it. The activity as such is sufficient to form a mass. Applause in the end of the performance is a mass behaviour manifestation. An individual opinion turns into a mass 'subconscious collective opinion especially in a public activity as described by Canetti. But the audience of the performance and the acceptors of an innovation differ because the latter do not sit next to each other as the theatre audience does. The acceptors of the innovation still, however, belong to the same communication network. In a communication network information is also transferred on a subconscious level.

The final stage of accepting innovations when many people act and think in a similar way is the stage when the innovation is written into the communal subconsciousness. The new opinion is accepted as a rule. Hereafter one starts to ignore the critics of the new opinion that is accepted as the rule. The principle - he or she who critiques our opinions is not one of us is put into action.

\section{The role of the subconscious when a baby learns to speak and forms its identity}

A community retains its communal subconsciousness despite the fact that generations vary. Information enters into a small child's subconscious mind from the communal subconsciousness. From birth to the age of six a child's brain activity is adjusted to programme his or her subconscious mind. An electroencephalogram (EEG) of a small child's brain shows that from birth until the age of two only a sleep-like delta vibration frequency can be detected. From the 
age of two until the age of six, in addition to the delta frequency the theta vibration frequency is also detected, that corresponds to daydreaming and dreaming. It is known that the subconscious mind is active during sleep and dreams are connected to the subconscious. Doctors who use hypnosis put their patient to sleep so that a brain state corresponding to the delta and theta frequencies is formed. They then insert new behaviour patterns into the patient's subconscious mind.

A conscious thought process cannot start from a blank space. The conscious mind functions only in conjunction with the subconscious mind. The computer works similarly. First an operation system is stored into a computer and only then can the user start working with programmes. But the role of human subconsciousness is wider than a computer operation system. An operation system normally does not interfere with a work programme but subconsciousness directs consciousness continuously and subtly.

From birth until the age of six common principles such as limits for accepted and forbidden behaviour, good and bad and dangerous and safe, instructions how to recognise good and evil, what belongs to you and what does not, classifying oneself (in other words identity) are written into a child's subconsciousness. Information enters into a child's subconscious mind from close relatives and also from more remote companions, meaning his or her identity circle.

The information that enters into the subconscious mind depends on time and place. Children in China do not get the same information as children in Sweden do. Contemporary Swedish children get different information than Swedish children did a hundred years ago. Children who are born at the same time and place but into families who belong into different social layers also get different information. There is a common opinion that at the age of six when children start school there are no differences in their consciousness and these are like blank pages that one begins to fill in school. Unfortunately this view is far from reality. Children in school are very different and teaching cannot alter the differences in their subconsciousness.

Mastering social behaviour patterns runs in parallel with mastering speaking. When a child grows up in an environment where there is no contact with humans (e.g. with animals as it has sometimes happened), then he or she will not learn to speak at all.

A child masters grammar rules without teaching. Mastering language happens via communication through two parallel processes. One part is conscious and verbal communication and the other part is unconscious (subconscious) and nonverbal. Information that is nonverbal also runs via communication channels on the subconscious level. Therefore a child will master grammar unbeknownst to himself or herself.

\section{Forming the public mind of a community of cells}

A collective mind that to some extent controls all individuals in a collective is not rare in nature. One of nature's common principles is repetition on different levels. If we look at trees we can see that thin branches form in the same way as thick branches. When the tree grows then the branching cycle repeats itself. This phenomenon is called a fractal pattern frequency and is the subject of fractal geometry. Unicellular organisms also developed into a community and the community formed a communal consciousness.

For the first 3.8 million years, there were only unicellular organisms on our planet - bacteria, alga, yeasts and initial animals. 700 million years ago cells started to form colonies where information was exchanged. Later the work distribution between cells was also developed, which is called differentiation. Organs, brains and brain programmes were developed, which is called consciousness. A different part of the brain developed - a prefrontal cortex. This gives a person self-awareness. The final result is the contemporary human being. Humans 
were developed because they are capable of adapting into nature better than unicellular organisms.

A human being is basically a cellular community that consists of 50 trillion individual cells and the human mind is the common mind of cells. Cells live in a person's body in an aquatic environment just as they did hundreds of millions of years ago in the ocean. Cells possess a certain independence. A cell membrane functions as a brain and communicates with extracellular space. Cells have emotions; they can be happy or sad. In the case of changes in the external environment cells can start to select and also change genes in the nucleus. Cells possess the ability to adapt to the environment.

If we look at cells individually then human beings cannot be found in any cell. Cells form the human body. We communicate with the human mind. And the enormous amount of body cells have no idea that this occurs. Human communication can be compared with computer communication. A computer has hardware and software. We communicate with computer programmes that form the software. Human cells correspond to hardware and the soul corresponds to software. If a human community is compared to a cell community then the cell community is ancient and perfectly developed. Compared to a cell community, the human community is, on the contrary, very young and only just developing.

\section{The hundred monkey effect and the behaviour of social insects}

Well known is the story of monkeys' behaviour - so-called hundred monkey effect (Wikipedia). Japanese scientists conducted a study of macaques`studying capabilities on the Japanese island of Koshima in 1952 by teaching macaques to wash sweet or yam potatoes in water before eating them and observing how this innovation spread among monkeys. The result generally corresponded to how humans accept innovations according to an S-curve. What was amazing, however, was that once a critical number of monkeys were reached then monkeys started to wash potatoes not only on the island where they were taught to do so, but also on the neighbouring island where monkeys were not taught, but observed for another purpose. This story is considered to be factual and described as such in several books. There are also authors who doubt its validity or label it as a paranormal phenomenon. There is no knowledge of repetition of such an experiment. The result of the experiment nevertheless indicates that monkeys' communal mind does exist. Furthermore the story also shows information traffic in monkeys' communal mind from one island to another "through the air".

Ants, bees and termites also possess a communal mind. It has been studied how a swarm of bees who leave the beehive with the queen bee when the bee colony divides finds a new hive location. Espionage is enacted by $5 \%$ of the bees. First they go and look everywhere in the neighbourhood. When the spies find something then they come back and let the others know through dance how good the new hive is in their opinion and in what direction it is located. If the hive is very good, then they dance for up to five minutes, in the case of a poor hive just 30 seconds. The duration of the dance indicates their opinion of the new hive. Bees who see the dance go and take a look at the good hive location. So the numbers of bees flying between the beehive and the new hive location starts growing. When at some moment there are 15 bees next to one potential hive location then a special signal is transferred to the beehive and the swarm of bes flies to the new hive location.

Every bee gave an individual opinion about the place that it had found. The data about these opinions was transferred to others through dance that substitutes human speech. Then on the basis of individual opinions a common opinion was formed. There was no meeting as is the practice of humans. Voting was substituted by observing how many bees were visiting one possible new hive location. Management like that can be called diffused control. 
Every individual bee had to know only that it should go and look for a new possible hive and the bee was occupied by this task until it saw that one potential new hive had another 14 bees around it. No one decides on the location of the new hive. The decision is made automatically. Bees act according to that algorithm and also change algorithms due to the communal subconsciousness. A bee colony is wise. A bee is not.

The building of a termite nest requires especially complex strategic management - in desert conditions a stabile internal climate with beneficial moisture and temperature is created. Creating this artificial environment is a complex task in contemporary engineering but termites have accomplished that already for hundreds of thousands of years.

If we take a broader look at different organisms then body cells, body organs and also social insects do not generally possess the habit of damaging their fellows. One does not harm their chums. But one does harm outsiders. There are wars between termite nests. But the lung does not declare war on the liver because they belong together. Nevertheless there is an exception to that rule - a cancer tumor. Cancer cells either do not follow the rule that you do not harm your chums or they do not see body cells as chums. Normal cells can attack cancer cells and destroy these - that is normal. But if normal cells take cancer cells as their chums and do not attack them then the organism will be destroyed. That is not rare either. It means getting cancer.

Building upon what has thus far been mentioned, a community where everyone seems as if they belong there and do not mutually harm each other can be taken as a diffused organism. If all mutually harm each other then there is no bloom as an organism. If some hidden damagers can be found in a community, it can be seen as an organism with cancer. The common practice of lying and deceiving in modern society should show us that this society is ill.

\section{How can we frame information transfer and saving in a diffused organism?}

In human society that could be seen as a diffused organism two types of information are transferred - conscious information through known pathways and subliminal or subconscious information through unknown pathways. How one should imagine subliminal information transfer routes or information "silently transferred through the air" is not clear at all. When describing how subconsciousness functions the actual information transfer route is normally not considered. It has been included neither in Canetti`s mass behaviour nor Jung`s collective subconsciousness.

Nevertheless it certainly is the case that inexplicable information transfer "through the air" does exist as it has manifested itself distinctly through the hundred monkeys effect. Similar transfer happens in telepathy that one does not generally dispute but cannot explain either. It has also been observed that people sometimes have the capability to foresee events - it has been called the sixth sense. This information broadcast is similar to a radio broadcast but the information carrier is not the electromagnetic field but some unknown field. The British biologist Rupert Sheldrake has called it the morphic field. Modern physics considers the existence of unknown low energy fields possible. Studying communal subconsciousness and mass behaviour shows that people in certain circumstances have the capability to read other people's thoughts though they do not realise it themselves and these thoughts could be either conscious or subconscious. People act as a diffused organism and information transfer of some kind is crucial. One could assume that the information carriers in communal subconsciousness are the fields that cannot be generated or registered by contemporary technology but biological objects are able to generate, feel and use these for communication. 
Diffused control is also used in technology. This solution in principle is known as a smart dust grid. A smart dust grid used in technology consists of many relatively low capacity information processing devices that are diffused in space, that have connection channels and that are together capable of solving even general, bigger tasks. Information moves as a transit through several devices and reaches the necessary receiver.

If we take an outside look at a community with its communal subconciousness then the communal subconsciousness seems to be a biological smart dust grid whose information processing centres are located in people's heads and the information processing channels between the centres are telepathic.

But if the observer belongs to a community and is in the community then the biological smart dust grid is an individual subject. Information does not come from any person, it comes from the grid. Some people sense this grid as if it were an unusual mysterious person or subject. This subject collects information, processes it with its own algorithms and gets a new result. Because of this new information the subject seems to have an intellect. This subject dictates its opinion to the members of the community through hypnosis. Therefore this subject seems to be self-righteous. Thus the observer who is in the community sees the biological smart dust grid as the subject possessing self-righteous intellect. But the activity of this subject does not reach most people's consciousness directly. Hence some people could sense it somehow vaguely and call this perception a God. According to Carl Gustav Jung the collective subconsciousness and God are practically one and the same.

The mysterious God who features in the form of the communal subconsciousness does exist and is located in the backstage of all our heads. Every identity circle has its own God. But atheists do not suspect that they also have their church-less religion that is hidden in their subconsciousness and that they are manipulated by it. Atheists have accepted the dogma that in every human's head there is an inexplicable information processing that gives rise to intuition. Unfortunately ideologies rising from this dogma cannot explain the processes in modern society.

\section{The mythological explanation of the communal subconscious through egregores}

The collective component in human behaviour has also been explained with reference to egregores. In religious mythology aside from God there are also angels. Egregores are psychic creatures that are similar to angels. These have been treated as immaterial formulations that rise from the common emotions and thoughts of a group of people. Thus the egregore has also been seen as a bodiless soul who has its own opinion and information processing. The egregore has also been called a joint field or a psychoenergetic field. Nevertheless there are researchers who try to overcome the conflict between mental and material and state that humans' association has the capability to create for them a communal immaterial mind that is called the egregore. (Konstantin Petrov. Mechanism vozdeistviya egregorov na cheloveka (Mechanism of egregores affecting humans). http://dokumentika.org/mirovozrenie/mechanism-vozdeistviya-egregorov-na-cheloveka

(03.03.2015). This viewpoint is very close to the statements that have been presented in this work. According to that definition the egregore is similar to the communal subconsciousness. But if we take a closer look then we can also see differences.

According to Petrov egregores are formed from humans' biofields and they also get energy from humans. Hence egregores are above persons; they do not belong to the human body as a hand or a foot does. Egregores have an independent capability to get information from the environment, process it and set goals. They are wiser than humans. They are also capable of forming surrounding circumstances for humans. 
Egregores are capable of placing hypnotic content into humans or into a group of humans. But a human can also place content into the egregore. The egregore can help or harm a human but can also control a person for a long time.

The characteristics of egregores as described by Petrov go along with the characteristics for an immaterial and invisible parasite who feeds from human biofields and who is capable of manipulating humans. But the communal subconsciousness is not an independent parasitising organism. The communal subconsciousness is an inseparable component of the diffused organism that is human society. The common part of the Petrov`s egregore and the communal subconsciousness is that they both get the energy that is necessary for their existence from humans and both are capable of placing hypnotic content into a human. Thus in both cases the existence of mass behaviour is acknowledged. But Petrov's statements about where humans gain the information that controls a mass behaviour are very different to the statements that are made in this work.

In this work it is stated that this guiding information for understanding mass behaviour is gained by processing information that is gained by observing human behaviour. The collection and processing of information is diffused. In principle it is the same kind of diffused control process as for controlling a termite nest. The termite nest is controlled so that there is no termite in control.

Petrov`s egregorian control therefore is centralised control led by the egregore. The egregore gets its information from arbitrary sources and processes it in its own way. Petrov does not say that the egregore has any limits for getting or processing information. To explain the phenomenon of the unknown leader of a mass behaviour Petrov introduces a new stranger the egregore who can do anything. But that presents new unanswered questions.

On the one hand the egregore has been given the characteristics of a harmful parasite and it has been described how he damages people, on the other hand it has been mentioned that the goal of the egregore is to guarantee that humans stay together and live on. How should one explain such conflict?

The egregore has also been called wise and described as something that sets personal goals. But where does the egregore's wisdom come from? Does it come from a presumable cosmic information field via a correspondent search engine or is there another information source somewhere - this has not been explained.

According to Petrov a human can consciously insert information into the egregore and thus manipulate it. How is the information transferred? Are there meetings or an exchange of emails or some other way to create an information channel with an unknown object that is located in an unknown place? That also leaves things unexplained.

Unanswered questions and contradictions also appear if one tries to unite things that do not belong together. It seems that Petrov has artificially united egregores who have their own free will, own goals and information sources with the part of the communal subconscious where information is transferred from the communal subconscious to humans. Petrov does not mention that the communal subconscious inserts its information only via humans. Petrov has defined the egregore incorrectly as the actual source of the inserted information of the communal subconsciousness. Therefore there is no acceptable explanation about where and how egregores gain their information.

On the other hand there is no reason to deny that egregores do exist. If they exist then they can also affect the communal subconsciousness in a so far unknown way. And this effect is similar to the effect of a strange organism that causes a disease. Thus the Petrov's egregorian control can be taken as the disease of the communal subconsciousness. Petrov`s mistake is 
that he has not differentiated sick and healthy communal subconsciousness. He has considered the pathogen to be a part of an organism and constructed a hybrid of a classical free egregore and the communal subconsciousness, unbeknownst to himself.

This hybrid cannot function informatively because the arbitrary harmful information noise flows into the hybrid's information system via the egregore. How the egregore joins the communal subconsciousness can be compared to how the tuberculosis rod joins a human organism. A tuberculosis patient could thus be called a hybrid of humans and tuberculosis rod. But a hybrid of this kind cannot function normally. A patient either gets well or dies from tuberculosis. The same applies to a human community whose subconsciousness is affected by the egregore. Via the egregore information noise (misinformation) is inserted into the communal subconsciousness and it destroys the community. There have been cases where people who were manipulated with misinformation went underground to wait for the end of the universe. But these cases are exceptions not the rule.

But if the communal subconsciousness is infected by the egregore (a disease) then it is a topic for ideological war.

The formulation of the egregore theory could be explained with reference to the communal subconsciousness as an objective reality of natural origin whose existence can be observed only indirectly as a result of some invisible and unknown subject's activity. People of many different nationalities have tried to describe this subject using fantasy. The result is a large number of different gods, angels and egregores. This similar fantasing of people of different nationalities can be explained with reference to the communal subconscious.

Unfortunately there is a modern atheistic ubiquitous attitude that no inexplicable psychic effects "through air" exist and all gods and angels are groundless fictions that have occurred to people spontaneously. The fact that the creation of basically similar myths in many isolated cultures spontaneously is highly unlikely to be possible, is simply ignored. 


\section{Part 3. The manifestation of communal subconsciousness}

\section{Mass behaviour}

Commonly known mass behaviours are panic, street riots and revolutions. In his book "Mass and power" Canetti uses the term "mass" and also describes other forms of mass behaviour. He includes religions and wars in the definition of mass behaviour. At the same time he has not defined a mass directly and shows no particular interest in the ways in which mass behaviour transfers information. There is no better explanation than that a mass behaviour is controlled by the communal subconscious. The effect of the communal subconsciousness is obviously in question if a large amount of people change their normal behaviour at the same time. And mass behaviour is exactly such a behaviour. A pure mass behaviour is the most recognizable form of communal subconsciousness. By describing mass behaviour one mentions mass actions but not human actions. Persons' individual thinking has been ignored as if it were switched off.

According to Canetti's studies one could define mass as a human herd where all are occupied by the same activity but have no previous agreement or external order or suggestion to do so. The subject that transfers information to a mass and information transfer channels is undetected and unknown. But it is clear that people had to get information from some source in order to act in the same way and sometimes even a little senselessly. The mass formulation and disappearance described by Canetti should be seen as the formulation and disappearance of communal subconsciousness. According to several mass behaviour cases described by Canetti one could conclude that a mass starts to form right away if the mass moves, acts or thinks similarly.

Canetti speaks of rapid masses that are short-term and have rapid processes within. For example, the interval between the mass behaviour beginning and ending in the case of panic is just a couple of minutes. He also speaks of slow masses that are long-term. These are, for example, religious masses that can last for thousands of years.

One special form of a mass is Canetti's gang. He sees the gang as the oldest and least common type of mass. The gang is firm and everyone knows each other. Gang behaviour is unsettled. According to Canetti gangs have had a special role in forming world religions.

Masses have to be classified on the basis of whether they occur in peacetime (e.g. visits to the theatre) or during a time of danger or war. In a situation of danger mass behaviour is significantly different. The typical mass behaviour in the case of danger is war.

Canetti is not particularly interested in the ways in which people act sensibly together by following cultural norms. Canetti is interested in the ways in which all people together act somehow purely and this is what he calls mass behaviour. Canetti has thoroughly studied mass behaviour. According to him a mass has a passion to destroy and preferably to destroy houses and people. Contemporary media also passes on the mass riot pictures of cars upside down and on fire.

Pure mass behaviour is dangerous, incomprehensible and scary. Behaviour such as this draws much more attention than everyday, adequate and unnoticeable mass behaviour. Mass behaviour is usually noticed if it becomes mass madness. There is a tendency to think that a mass behaviour can only be a negative phenomenon. If all act correctly in a similar way, for example start using mobile phones or the Internet, then normally no one speaks of a mass behaviour. This behaviour is considered to be a private choice. 
Due to the exaggerated importance placed on pure mass behaviour, a negative attitude towards masses as a whole has developed. At the same time representatives of societal layers who are close to power do not see themselves as a part of any mass. Conversely people who do more simple work are called an uneducated mass. Actually people who are close to power form their own identity group, they have their own communal subconsciousness and mass behaviour. Only eremites who lack a communication circle can be free from communal subconsciousness. People who are close to power and rich people can also be affected by a pure mass behaviour. The real estate boom in 2008 was an example.

\section{Religion and belief}

Global religions such as Christianity and Islam consist of three parts. These are God Jehovah or Allah, Holy Book - either the Bible or Quran and unwritten behaviour rules which are part of the communal subconsciousness. Shamanism did not have a God or Holy Book, it only had rituals and unwritten behaviour rules. All societies have behaviour rules that are generally followed unconsciously and violators are punished. Punishment could be just a slighting attitude. But old Jews stoned people to death and in the Middle Ages there were crusades.

Atheism is at war with religions and belief. Does God exist? This is an ancient dispute. Nowadays most Western people think that there is no God. But that is an unproven opinion and one cannot even start to prove it before God has been defined similarly by everyone. Yet there is still no generally accepted definition. Believers and deniers of God possess a different image of God.

There is the fact that people have believed in God already for thousands of years and built countless temples, churches and mosques. If there is no God then absolutely all nations have acted as mad people who cannot detach reality and fiction and construct useless buildings or follow absurd religious rituals. It is hard to believe this. One can think that temples were necessary for people themselves and not for undefined gods. What necessity could this have been?

Temples are places for gathering. Gathering is a common activity that satisfies people's native need for communication which is a mental activity (a communal activity does not have to be aimed at satisfing just material needs). Being in nice company affects human psyche as if it were a drug with no negative consequences. Therefore different festivals are arranged and that is also how Estonians organise their song festivals. Following rituals is also a communal activity. During the communal activity people have similar thoughts and if their activity is successful then a communal subconsciousness forms that unites people and forms a mass.

Being part of a mass gives you a positive emotion. God's name then is only a symbol that leads to participation in the mass and to the communal subconsciousness that is connected to it. The ancient dispute and mess are caused not by God but by the communal subconsciousness. The communal subconsciousness does exist; it has an impact, but is imperceptible. An altogether different question is whether the communal subconsciousness also has information channels for communication with some mental creatures whose mental level is higher than humans' and which one could consider to be God. There is no proof that there is but there also is no proof that there is not.

Atheists consider religion to be harmful. Liberals think that religion is harmless and useless. In some Arabic countries the Holy Book is basically the state's constitution and all the statements against religion are punishable. Who is right?

Religions are historically connected to power. The rulers of the old Mayans were the godkings who among other things had to time the rain correctly for farmers. Power forces the 
members of a society to follow the rules. Religion gives rules. Following the rules is necessary for social work division to function effectively. The better the work division and mutual understanding, the stronger the community. A community with the same religion and a power structure which forces everyone to follow religious principles is stronger and therefore religion and the power that supports it have emerged and stayed.

The biggest problem in the division of labour in a society is to divide work results fairly according to input. Here religion can help with the legitimising and following of rules. These rules for just interaction are normally called morals. The main moral principle could be "my own wellbeing through supporting the wellbeing of my peers". This principle also features in Christianity and is called Christian love. The opposite principle is "my wellbeing on the account of others"'. The first principle produces a Nordic welfare state. The other principle produces a poor country infused with crime. Morality and welfare are in strong correlation. Christian morals do not reflect a self-centred but instead a suprapersonal or transpersonal worldview. The attackers of Christianity would like to receive welfare on account of others, not through the welfare of others.

Rules for the division of labour are necessary in every society. The following of these rules can be accomplished in at least two ways. First through beliefs where the rules are in people's subconsciousness and they follow them automatically without surveillance. Second through legislation where rules are written into laws and the police and courts ensure that they are followed. The use of beliefs is cheaper and more effective. Police and court systems are expensive and inefficient. Crooks are very inventive and find ways to get around laws. Religion also does not force all people to follow laws. Some of the so-called dissidents try to break the law anyway. Therefore the police and courts are necessary in any case. But whether $5 \%$ or $55 \%$ of the population is made up of potential lawbreakers makes a big difference. If the majority of people try to break laws then the police and courts are not able to successfully fight against it. The criminal contingent also infiltrates security organs. Beliefs with the right message are a very good tool for securing discipline and harmony in society. Beliefs here are not considered to form one of the world religions but instead refers to moral norms that are similar in most religions.

The trouble with a religion which has a Holy Book is that you cannot correct the message in line with new ideas that spread in a society. A Holy Book has been declared to be the words of God and God has been declared to never be wrong. If one tries to renew the religion then one has to admit one of two things - either the Holy Book does not consist of the real words of God or God can make mistakes also. In both cases the image of the religion suffers.

Yet religion has been renewed. For example Martin Luther's action led to the forming of a new Lutheran church that broke away from the Catholic church. If one were to look at country rankings that are compiled by the Human Development Index of the UN, then Protestant states are on the top of the chart and outperform Catholic countries. Martin Luther's work is still productive despite the aggressive attack of atheism.

The answer to the question "Is religion necessary?" could be that with suitable messaging it is useful and beliefs should be developed in line with the development of the society.

One of the biggest problems of modern Western society is the disunity of the communal subconsciousness due to the impact of multiculturalism and the pure effect of religion on improving social cohesion. Scarcity of social cohesion causes deficiency in happiness levels that one tries to soothe through pathological sex and drugs. Ignoring religions' moral norms has also led to increased crime and corruption. 


\section{Cultivated godless religions}

Religions have been formed spontaneously since the beginning of recorded time. But cultivated godless religions are a manifestation of recent times. These religions have been started by philosopher-reformers such as Karl Marx. Philosophers' theoretical constructions have been put into practice and thus produced a new societal structure. The 1917 Russian revolution is an example. During this revolution the previous religion, Russian Orthodoxy, was destroyed. Churches were plundered and clergymen killed. The whole societal structure was reconstructed. Private ownership was abolished.

As a result of this the nation's communal subconsciousness was slowly changed. After the Second World War a new communal subconsciousness with new values was developed in the Soviet Union. A living human being took the role of God. That was the ruler of the state Joseph Stalin. When he died the mourning was unprecedented.

In the constructed conditios of social cohesion which had produced a communal subconsciousness an error endagering existence was hidden. That was the reason why the Soviet Union fell apart in 1991. The theorists of the new order were not familiar with communal subconsciousness and could not foresee the danger. These theorists did not know that communal subconsciousness can accept and magnify lack of success so that it becomes dangerous to society.

Human society stays together because the division of labour improves the capacity to cope in the natural environment. Inevitably cheaters always exist who do not want to work and try to live at the expense of others. If these cheaters are in power then they will be engaged in corruption, get rich and will be successful in the eyes of the rest. This is where the unknown biological information system of human society - the communal subconsciousness - is poorly applied. It signals subtly to people's subconscious that the actions of the cheaters should be imitated. And almost everyone in society, except the dissidents starts to imitate the cheaters without criticism. Everyone starts expend energy to seek possibilities to push the labour onto someone else either through corruption or by some other means. And they will indeed find some way to do so, with the result that parasite-like habits start to dominate in the society.

In Russia in 1917 communists used the help of criminals to get to power. Long-term prisoners got positions in the new government. Criminals have their own common identity and their own communal subconsciousness. Criminals are normally shirkers who want to live like parasites at the expense of others. Clerks have a privileged position. Shirkers took this privileged position. Normal people noticed it. They started to accept the thought patterns of the criminals because this guaranteed success. The state started to steal massively. Unnecessary positions for "light work" were created in order to get a state salary without working. The success of criminal thought patterns was also noticed by normal people's communal subconsciousness. The communal subconsciousness inserted into everyone's mind that criminal behaviour is useful as a new beneficial invention. Due to this kind of behaviour the production of goods that were useful for people decreased. People began to fake the fulfilment of the national production plan which was at the time considered to be the basis of the state capitalist economy. In Uzbekistan this went so far that the difference between actual cotton production and the numbers on paper was enough to fill whole train wagons of cotton. The wagons' disappearing act was staged.

The economy functioned in the situation where there was money both for people and for enterprises, yet people could not buy necessary goods with this money. A system of exchange between acquaintances was developed where deficient services and goods were mutually exchanged. To get a clerk to give you permission to buy a piece of land for a summer house or a car you had to bribe him or her. The corruption spread and laws were massively broken. 
But people were not allowed to tell the truth about the situation. This was called anti-Soviet propaganda and carried prison sentences as punishment.

But when the situation got to the point that shops were completely empty and people were about to starve, general dissatisfaction arose and the state fell apart. The basis for state failure was that everyone wanted to live well without working and the communal subconsciousness started to intensify that attitude.

When Karl Marx studied social relations in his time then he figured out that people value going to work and working. Marx thought that the wish to work is natural to humans, it is in their instincts. But Marx was wrong. The wish to work at that time was in people's communal subconsciousness. It was not a part of human instincts at Marx's time and nor is it now. At Marx`s time working people were more successful than unemployed people. Therefore people`s communal subconsciousness inserted into everyone`s mind that working is useful and a successful behaviour. But by 1991 the Soviet Union that had been developed by Marx`s theories had developed into a situation where all people considered honest work to be a silly activity.

To improve the world through self-made rules and implement spontaneous ideologies when one does not know or ignores the effects on communal subconsciousness is dangerous. Karl Marx could not foresee the general despising of work. Vladimir Lenin (Ulyanov, $1870-$ 1924), who established the communist state, did not know to take into consideration that by having criminals in government the criminal ideology would spread all over the state. The deepest reason for both errors was that the existence of communal subconsciousness was not known and one could not foresee that it interferes with planned scenarios.

It is dangerous if shirkers reach positions of power. Fighting against cheaters is more important than it is commonly thought. It is a question of society`s immune system. Cheaters are the cancer tumours of society. They do not follow the rules of communal life. If important rules are not followed then both the organism and society are destroyed. It is not important whether the society is market-based or socialist or some other type. Criminal ideology destroys all societies through one and the same algorhythm. And in this algorhythm an important role is played by the unknown weak spot of communal subconsciousness communal subconsciousness is shortsighted and may also accept a failed success.

In 1991, the Soviet Union did split up, but the experiment that had begun in 1917 had not yet ended. Over 70 years a peculiar collection of behaviour patterns had formed in the Soviet people's communal subconsciousness. The following of these patterns during the new regime was also dictated by the communal subconscious. These Soviet-time patterns have had a strong effect in all the former Eastern Bloc countries. The behaviour patterns were formed in the conditions of an artificially created society structure where constant brainwashing for creating a new human being was conducted. Thus a new godless religion was created where the missing role of god was filled by communist theorists Marx, Engels and Lenin and whose Holy Books were these theorists' works.

After the Soviet Union split up, East Germany where the godless religion had also emerged, joined the West Germany. But then during the transition from socialism to a market-based economy strange unforeseen obstacles occurred. East Germans called Osses, behaved in an incomprehensible way. And the explanations for how to behave in the new regime were not successful because the Osses had different beliefs. The view that "Osses will always be Osses" spread.

Since 2008 economic growth has stalled in the whole world. One cannot exclude the possibility that one reason for the stalling of economic growth has been the unnoticed 
transmission of criminal liberal ideology from the Eastern Bloc to the whole world. Also in Western countries one can perceive the trend of increased lying and hypocrisy, though it has not yet reached the level of the former Soviet Union. Lying always has the same common goal - force someone else to work and use the result of that work for oneself. If everyone starts to follow this criminal pattern of thinking then the downward spiral is inevitable. Unfortunately a person who has a me-based thought pattern is not able to imagine that others could start to cheat them as well and therefore they cannot see the danger of their dirty tricks to the full extent.

Through its unnoticeable activity, the communal subconsciousness also affects those who should guarantee order and the following of laws. The police take a liberal attitude towards corruption, other crimes and simply injustice. Without any perceptible reason a process that weakens the whole society is started.

The antropology professor David Graeber (London School of Economics) comments on the analysis of employment comparing the year 2000 and 1910 in the USA and finds that the number of employees working in industry, agriculture and domestic servants has decreased considerably. At the same time the number of employees in management, offices, sales and services has tripled. If earlier these people formed a quarter of all employees then now they form three quarters. It is understandable that employment in production has decreased due to automatisation. But Graeber considers this enormous increase of the admistrative sector unnecessary and incomprehensible. Many people in the administrative sector understand that their work is pointless. Nevertheless they do not want to take up productive work. According to economics theory an enterprise aiming to gain profit does not pay salaries to useless employees. But the situation has emerged and still remains.

Presumably the reason this situation has come about is that working in the admistrative sector is considered a sign of success. The communal subconsciousness inserts into people's minds how to behave successfully and people develop an obsessive thought that dictates it is useful to get a position in the administrative sector. So everyone seeks the possibility to get work in the administrative sector.

The action mentioned above illustrates behaving according to accepted habits that can change because people learn about accepted habits primarily from the subconsciousness. But there is a widely spread misunderstanding that similar behaviour comes from genes and that to find easier work and live at the expense of the others is natural. According to this misunderstanding we should genetically engineer a human being who is glad to work. Actually we do not need a new human being. If work is respected then people work gladly. The same communal subconsciousness makes work become respected through its hypnotic insertions. It happens if work really is the most successful strategy for life and if people in power confirm this with their actions. But if cheaters are in power and demonstrate through their actions (words are not important here) that without work one can live very well then after some time no one works with passion anymore. The criminal mentality that only fools work takes over. This mentality is dangerous to society. Criminal ideology does not acknowledge laws and ruins the functioning division of labour. Criminal thinking slowly destroys the existing social structure and savagery sneaks in to replace it - the stronger one is always right. Slowly everyone starts to accept breaking laws and abnormality becomes a norm that is justified by liberalism.

\section{War}

Changes in social opinion are different during peaceful times and in an emergency. During a period of peace rapid changes in opinions are caused by similar individual opinions or 
changes in opinions that spread in communication networks by chain reaction and eventually cause a rapid transition from individual opinions to social opinions.

In a situation of danger or emergency, however, the communal subconsciousness uses different control algorhythms. One person's actions might be sufficient and if others observe these then the whole group starts recklessly imitating. For example one person runs off in a panic and right away others start imitating them recklessly. Even just one opinion about a potential danger could turn into a commonly accepted norm similar to a dogma.

Elias Canetti has found that, in the case of danger or war, a special fierce sensitivity and irritation towards an enemy who has been definitively defined as such occurs. The defined enemy can then act as a friend but it makes no difference anymore. In situations of danger companions and outsiders are also defined on the basis of who is for us and who is against us. Outsiders are seen as potential enemies. Neutrals are also counted as potential enemies. Confrontation can lead to war. Canetti considers that war is a mass behaviour and as an example he presents a war cycle from earlier times:

1. first one dead;

2. funeral;

3. forming of a revenge force;

4. vdestroying the enemy, capturing prisoners;

5. prisoners' public execution; public celebration;

6. increase of the sense of unity and king`s power.

The question emerges why it is so easy to form a revenge force. Soldiers who go to battles cannot be sure that they will not get killed. But somehow soldiers who go to a battlefield have hope that they will not be killed but instead they will kill the enemy and become heroes.

The modern war cycle does not normally include the execution of prisoners but the announcement of the first one killed always makes people nervous. Immediately some people want to go and take personal revenge. The communal subconsciousness releases the war cycle also nowadays, but according to contemporary conditions. The suicide terror attacks on November $13^{\text {th }}, 2015$ in Paris and in March $24^{\text {th }}, 2016$ in Brussels have obviously started the war cycle in Europeans' subconsciousness. The same is shown by the forming of spontaneous national movements in several European countries (Germany, Sweden, Finland and elsewhere) who call themselves the Odin warriors. The number of people supporting the nationalist parties is also increasing.

But there is also another side to the story. It is easy to turn a mass dangerous if you make innocent people look like enemies through lies and betrayals. The problem is that a community`s communal subconsciousness does not control signs of danger. Or at least does not control them thoroughly. The first one killed starts a war cycle. And war can grow big.

The Roman commander Julius Caesar fought in Gallia for ten years, conquered eight hundred towns, fought against three million people, killed one million of them and captured one million. Whether those killed and captured were just strangers or dangerous enemies Caesar's soldiers was probably not questioned at all. Nowadays it is also easy to paint strangers as enemies.

Do people have a natural genetic tendency to go and kill strangers? Probably not. Canetti describes the Pueblo Indians who are not interested in wars and do not fight. He also describes Jivaro who live in South-America and cannot imagine life without war. No one has heard of a war gene so far. The reason for a war-oriented disposition is obviously in the communal subconsciousness. The programme which the communal subconsciousness has 
follow is followed until some outside event is able to forcefully end that programme. The war-like disposition continues if it is not forced to be eliminated.

\section{Unsolved conflicts caused by differences between the communal subconsciousness of different communities}

A classical sign of the beginning of war is the first one killed but usually on some level there conflict exists already before this. Street fighting also usually begins after an exchange of insults. The terror attack on September $11^{\text {th }}, 2001$ started a war cycle that ended with the capturing, taunting and executing by hanging of the President of Iraq Sadam Hussein on December $30^{\text {th }}, 2006$. But the terror attack of September $11^{\text {th }}$ was still caused by the longlasting conflict between the values of the Islamic and Western worlds. The war in Iraq did not resolve that conflict. And could not have resolved it because the conflict is between the two civilisations' communal subconsciousness. The war in Iraq was pointless. In order not to repeat these wars in the future it is necessary to better understand communal subconsciousness and to take it into consideration.

Every community and nation has communal subconsciousness. This communal subconsciousness can for some reason accept a mistaken attitude and also amplify it. The communal subconsciousness inserts the mistaken position into the whole nation's minds and the nation is not able to see the truth anymore. Foolish collective stubbornness forms. Stubbornness is a presumption that is not possible to change through explanations and persuasion. The rule of thumb that the nation is never wrong does not hold well. Infallible communities and nations do not exist. The terror attack on September $11^{\text {th }}$ in New York, the Cuban crisis and the conflict between entrepreneurs and employees mentioned above were all caused by the stupid collective stubbornness that is in turn caused by the communal subconsciousness.

Every nation and every community has its own identity and its own unique communal subconsciousness. Therefore there are always conflicts in different communities' communication with one another. In principle it should be possible to solve any conflict through negotiation. But negotiators belong to different communities. One cannot perceive one's own community's mistakes because these mistakes have been hypnotically inserted into their mind. These mistakes one can notice only from the outside. Each person's opinions and positions can be divided into two parts. Some opinions and positions are individual and others are identity-based that have emerged as a result of input from the communal subconsciousness of the correspondending identity circle. A person themselves cannot see the difference and if the communal subconsciousness has made a mistaken insertion then the person presents that mistaken position while believing that it is correct. Even futher. They also do not listen to any explanations that show that it is wrong.

The mistaken opinions that have caused conflict sit firmly in parties' negotiators heads. Negotiations do not necessarily produce any results. And this is so even despite both parties' honest wishes. It seems as if the opposition has lost their senses. And both parties have the same feeling. These parties could be the governments of nuclear states. They see the other state as a gang of crazy people with a nuclear bomb. Naturally they think of scenarios of how to save the world from crazy people. But they are unable to understand that they too form a gang of crazy people if one looks from a different angle.

We all have our own identity and very likely also some identity-based misunderstandings or blindness to identity. Due to the blindness to identity we do not agree with recognising these opinions as misunderstandings if someone points these out with good reason. The phenomen of blindness to identity is in the communal subconsciousness and no one can destroy it. It seems as if nature has formed a human being with the inclination to obey the majority's opinion and support it blindly. 
Mistakes that are made by those in power, are noticed by those who are not in power. Those in power are as blind towards their mistakes as the society which it governs and despicably calls a blind mass. One person does not execute power. The people in power possess their own communal subconsciousness and blindness to identity. In reality power is also a mass. Therefore an opposition is necessary. But there is not much use for the opposition if its opinion is ignored. Exchange of opinions between those in power and the opposition allows the avoidance of mistakes. But if there is a war with the opposition as in dictatorships then the communal subconsciousness of both parties block information exchange. The communal subconsciousness starts to distort the opposition's information and objective discussion becomes impossible.

States and whole civilisations can also be at war. Then the information that comes from the opposition is also distorted by the communal subconsciousness and normalising relations becomes very complicated and takes a long time.

It is often thought that by making cultures identical it is possible to solve such problems. For example the Westerner goes to another civilisation wishing to help the people who live there and to bring them culture. Thereat the Westerner presumes that all people think freely and can freely change their opinions if the correct way is shown to them through explanations. But alas the explanations seem to produce no result at all. The wars in Iraq and Afghanistan did not noticeably democratise these societies.

If there is an incorrect text on a computer's hard drive and one loudly tells the computer to correct it then nothing happens. A person's subconsciousness and the community`s communal subconsciousness are like a computer's hard drive. There are rules for changing information. For the computer you need to open the file and use the keyboard. Speaking out loud does not have any effect on the computer. It also does not have any effect on the subconscious. In order to change an attitude in the communal subconsciousness, a positive experience gained by massive joint action is needed as we explored above.

People form different civilisations, for instance Muslims, have their own "hard drive" and Muslims' convictions have been inserted into their heads since birth from that hard drive of the communal subconsciousness. It is not possible to change these at once by using explanations or examples. These people need a massive positive experience which shows that the offered example is useful to follow.

\section{Global monoculture, territorial cultures or development of multicultures}

Modern high technology provides us smart phones, computers and TVs. These are complex devices and developing and producing these is useful only with high production capacities. The need for enormous enterprises has arisen. Many firms that at first only operated in one country have become global. For example the Brown Bover in Switzerland and ASEA in Sweden co-operated and became ABB which has specialised in energy devices of high capacity.

Global firms move their factories all over the world and try thus to raise profit. People in global firms move in the world's different regions and experience additional problems due to cultural differences. From their point of view the ideal solution would be a worldwide monoculture. The mutual enrichment of cultures is talked about and it is thought that if people who belong to different cultures live together then a new culture develops that is better than the original cultures that have formed this multiculture. It is hoped that all good survives and all bad becomes extinct.

This is the theory but what is the reality? Chinese and Arabic groups have formed their own districts in European cities. The second and third generation of immigrants has been exposed 
to cultural ifluences from both sides and should be more than averagely successful. In reality there is more unemployment and crime among them than in the general population. But there are also other observations. If there are just one or two immigrant children in a school class then they are often more successful than the general population. Why such differences?

Let us look in detail at how the rules of different cultures can form the rules of a new multiculture. For example let us look at traffic. In England there is left-hand traffic and in continental Europe there is right-hand traffic. In theory a multicultural traffic should automatically be the best choice. It is obvious that left-hand and right-hand traffic are equal. Should multicultural traffic use them both at the same time then? Surely not. At first similar rules are necessary. Then we can foresee the behaviour of others in traffic and the traffic functions.

If two cultures are united then obviously there are many equal but also different habits. Which of these will dominate? The local habits should dominate. Locals form the majority and they will never change their habits for an unknown habit that is not better than their own.

But if a new immigrant's country of origin has given them the belief that the habits and culture of their new country are good then they try to follow them eagerly. If that immigrant has children then the positive view of the new country's habits and culture is automatically passed to the child's communal subconsciousness. If the child grows and starts school then he or she already has a preliminary positive view of their peers, teachers and the content of their studies. That child successfully picks up subjects and along with that also local social habits. $\mathrm{He}$ or she is normally successful in their future life.

But if in the immigrant's country of birth there is a belief that their habits and culture are the best in the world and all others are worse then the immigrant has a negative preliminary belief about their new country`s habits and culture. For instance it is commonly believed in Islamic countries that all atheists are underdeveloped. That kind of immigrant follows the rules of their new country unwillingly and if they have children then their negative attitude towards the new country`s habits and culture is passed automatically into the child's subconsciousness in the first years of the child's life. When that child starts school then he or she will be in trouble. The child has a subconscious doubtful attitude towards their peers and teachers. The child does not feel they are a member of the school family. He or she has no particular interest in going to school and studying attentively. He or she also will insufficiently master the skills of social behaviour. They will not be successful when growing up. They will easily be in orbit of the police and courts. They will get the idea that authorities harass them because of their origin and they will find co-thinkers in local criminal circles. They may become asocial. By having a despising attitude towards the local culture the immigrant unknowingly turns their descendants into asocial people who have no expectations to act successfully neither in their new country nor in their parents' homeland.

If the second generation of immigrants forms an asocial attitude then they do not merge with the society of their new country but keep to themselves. An immigrant community forms which differs from the native residents. A conflict between communities emerges when the communal subconsciousnesses of these communities have significantly different opinions that are reflected in values and behaviour patterns. Thereat neither community sees a reason to alter their behaviour according to the others' rules. If one community is small enough (less than $25 \%$ of the people) and spread out then they sense the need to follow the rules of the majority and the number of cases of rule-breaking become so insignificant that it does not bother the majority substantially. In that case normally no conflict is formed. But if communities are of the same size or if the immigrants have formed their own colonies then 
both behave according to the rules of their communal subconsciousness that evokes mutual irritation and conflict.

During conflict the communal subconsciousness has a tendency to label the opposition with non-existent faults in order to present the image of the enemy more clearly. Both parties are far from estimating the situation objectively. Those who call for objectiveness are labelled as traitors. An internal conflict can expand into the conflict between the immigrant's homeland and the new host country. Though it can only happen if the immigrant's homeland is big and powerful enough.

The communal subconscious conflict might become bloodshed but it can also stay on the level of a so-called cold war. Then one another's life quality is mutually spoiled. The wellknown example is North Ireland.

Mutual enrichment of cultures is possible only between cultures that have mutual respect and understanding. But if there is a despising attitude or if one party exports their culture forcefully then the information in the communal subconsciousness is distorted so significantly that nothing will be passed from one to another. Unfortunately the developers of multiculture are not familiar with the effect of the communal subconsciousness. Therefore the conflict between natives and immigrants has formed in Europe and the wars in Iraqi and Afghanistan have not produced the desired result.

Every community normally has its own location or territory. A human being has an internal need for a territory where they know everything and where everyone behaves according to known rules. One feels that they belong there and is happy. The communal subconsciousness connects the rules to the location or territory. It is irritating if someone (a friend or stranger) violates these rules at home, on their own territory. Outside this territory in the company of strangers, it generally is acceptable not to behave according to the local rules.

If strangers invade the territory of a nation and forcefully import their behaviour patterns, if the natives are not able to forcefully stand up to them, they become stressed. According to natives' values things are being done wrong and natives cannot prevent it. They do not accept the invaders' behaviour patterns. Teaching and explaning does not help much. To break free from stress people start to drink alchohol, the nation's mental health deteriorates and the nation starts to become extinct. That was the situation with the indigenous people in the USA who survived after the wars. Nowadays the same situation faces, for instance, the small nations in the Siberian petroleum production regions.

During globalisation the invasion of foreign ideology and behaviour patterns is inevitable. But as it also has a negative side then a dilemma emerges: should we retain the nation and have limited globalisation or choose limitless globalisation and then nations vanish?

What would be the advantages of the disappearance of nations versus the global monoculture? On the positive side if a misunderstanding forms in the communal subconsciousness of a monocultural nation then it does not cause any conflict. There would be no different opinions because global subconsciousness makes the same insertions to everyone. Despite the overarching misunderstanding in some questions peace and harmony would still dominate.

But if following that misunderstanding produces a negative result then the mistake would be searched for and not where it actually is located. The real reason for the mistake is hidden by the blindness to identity that social psychology calls the effect of kaleidoscopic idiotism. Dissidents into whom the communal subconsciousness could not insert anything will of course find the real reason for the mistake, but the opinion of dissidents will be obstinately ignored. Sooner or later things become really bad globally. An example of such as global failure is the recent exaggerated real estate investments and their sad consequences that 
emerged in the economic crisis in 2008. If China and India would have also fully followed the European bankers' actions then the devastating effect of the economic crisis would have been several times bigger and the recovery of the economy significantly slower.

If we look at nature then we see that different plant and animal species have lived together for hundreds of thousands of years but during that time no best plant or animal species for each climate has developed and all other less valuable species have not become extinct. But there is also no opposite extreme. Every single tree in the forest is not of a different species. There is a balance in nature between similar and different. We should be careful with our wish to form a global monoculture.

Monoculture is good within one state and nation. A world where there are many national cultures is more viable and stable than a monocultural world. The pure behaviour of one nation has little effect on the world of several national cultures. But to prevent different cultures turning the world into hell through fighting, one has to reach the understanding that it is not possible or necessary to force different nations to think and behave similarly. Every nation should decide for themselves if they would like to accept other nations' innovations or not.

Here is the summary by the author. The full text is available in Estonian at the website: http://digi.lib.ttu.ee/i/?4216. 